\title{
Flow Pattern and Heat Transfer past Two Tandem Arranged Cylinders with Oscillating Inlet Velocity
}

\author{
Jian Liu ${ }^{1,2}, \quad$ Gongnan Xie $^{2, *}, \quad$ Bengt Sundén ${ }^{1, *}$ \\ ${ }^{1}$ Division of Heat Transfer, Department of Energy Sciences, \\ Lund University, P.O. Box 118, SE-22100, \\ Lund, Sweden. \\ ${ }^{2}$ Department of Mechanical and Power Engineering, \\ School of Marine Science and Technology, \\ Northwestern Polytechnical University, \\ Xi'an, 710072, Shaanxi, China.
}

*Corresponding Author.

E-mails: xgn@nwpu.edu.cn (G. Xie), bengt.sunden@energy.lth.se (B. Sunden)

Tel: +86-29-88492611; Fax: +86-29-88495278.

(C) 2017. This manuscript version is made available under the Elsevier user license http://www.elsevier.com/open-access/userlicense/1.0/ 


\begin{abstract}
Unsteady laminar convective fluid flow and heat transfer past two cylinders in tandem arrangement is investigated. Besides forced mixing by the natural vortex streets, extra imposed oscillating inlet velocity are considered. The lift and drag coefficients and Strouhal number for a single cylinder and their dependence on Reynolds number are also provided to validate the calculations with previous experiments. Different frequencies and amplitudes of the oscillating flows are set as inlet boundary conditions. For the cycle effect, at some specified points of the cycle ratios, the heat transfer enhancement of the upstream cylinder and the downstream cylinder are relatively larger due to the combined-effect of the natural vortex streets and the imposed oscillating inlet flows. The interaction between the natural vortex streets and imposed oscillating inlet flow leads to non-regular shaped vortices with increased flow mixing. For the amplitude effect, Nusselt numbers of the two cylinders are both greatly increased with increased amplitude ratios. With increased amplitude ratios, the vortex street expands and vibrates in a larger region which leads to stronger flow mixing and higher heat transfer. Generally, oscillating inlet flows can efficiently increase the heat transfer of two cylinders in crossflow without increasing the flow rate of the coolants.
\end{abstract}

Keywords: Vortex streets; Oscillating inlet flows; Cycle ratio; Amplitude ratio; Heat transfer. 


\section{Nomenclature}

$$
\begin{aligned}
& a=\text { amplitude ratio of the oscillating inlet flow } \\
& C_{D}=\text { drag coefficient } \\
& C_{L}=\text { lift coefficient } \\
& c_{\mathrm{p}}=\text { heat capacity }(\mathrm{J} / \mathrm{kg} \cdot \mathrm{K}) \\
& D=\text { diameter of the cylinders(mm) } \\
& f=\text { frequency }(\mathrm{Hz}) \\
& F_{X}=\text { force in the streamwise direction } \\
& F_{y}=\text { force in the spanwise direction } \\
& h_{\theta}=\text { local convective heat transfer coefficient }\left(\mathrm{W} / \mathrm{m}^{2} \cdot \mathrm{K}\right) \\
& h_{\text {avg }}=\text { averaged heat transfer coefficient }\left(\mathrm{W} / \mathrm{m}^{2} \cdot \mathrm{K}\right) \\
& k=\text { thermal conductivity }(\mathrm{W} / \mathrm{m} \cdot \mathrm{K}) \\
& L_{\text {total }}=\text { length of the computational domain (mm) } \\
& L=\text { distance between two cylinders (mm) } \\
& N u_{\theta}=\text { local Nusselt number } \\
& N u_{\text {avg }}=\text { averaged Nusselt number } \\
& p=\text { pressure }(\mathrm{Pa}) \\
& \text { Re }=\text { Reynolds number } \\
& \text { St }=\text { Strouhal number } \\
& T \text { = fluid temperature (K) } \\
& T_{w} \quad=\text { wall temperature (K) } \\
& T_{\infty}=\text { free stream temperature }(\mathrm{K}) \\
& T_{\text {inlet }}=\text { cycle of oscillating inlet flow (s) } \\
& T_{\text {vortex }}=\text { cycle of natural vortex street (s) } \\
& t=\text { time (s) } \\
& U_{\infty}=\text { mainflow velocity }\left(\mathrm{m} \cdot \mathrm{s}^{-1}\right) \\
& u=\text { velocity component in } x \text { direction }\left(\mathrm{m} \cdot \mathrm{s}^{-1}\right) \\
& v=\text { velocity component in y direction }\left(\mathrm{m} \cdot \mathrm{s}^{-1}\right) \\
& v_{\text {avg }}=\text { averaged velocity }\left(\mathrm{m} \cdot \mathrm{s}^{-1}\right) \\
& W \text { = width of the computation domain (mm) }
\end{aligned}
$$

\section{Greek symbols}

$$
\begin{aligned}
& v=\text { air kinematic viscosity }\left(\mathrm{m}^{2} \cdot \mathrm{s}^{-1}\right) \\
& \rho=\operatorname{density~}\left(\mathrm{kg} \cdot \mathrm{m}^{-3}\right) \\
& \alpha=\text { thermal diffusivity }\left(\mathrm{m}^{2} \cdot \mathrm{s}^{-1}\right)
\end{aligned}
$$




\section{Introduction}

Forced convection heat transfer around circular cylinders has many applications in engineering such as gas turbine cooling, heat exchangers, nuclear fuel rods etc. Heat transfer enhancement and crossflow of a circular cylinder or other shaped cylinders have drawn sufficient attention by researchers [1-12]. Buyruk et al. [1] conducted a numerical and experimental study of the laminar flow and heat transfer characteristics of a cylinder in crossflow at Reynolds numbers of 120 and 390. For the Reynolds number of 390, they obtained a better prediction by the numerical calculations compared with the experimental results. Forces were measured by Hover et al. [2] at both ends of rigid cylinders with a span $60 \mathrm{~cm}$, performing transverse oscillations within an oncoming stream of water, at $\operatorname{Re} \approx 3800$. Catalano et al. [4] studied viability and accuracy of large-eddy simulations (LES) with wall modeling for high Reynolds number complex turbulent flows considering the flow around a circular cylinder in the supercritical regime. However, the Reynolds number dependence was not captured, and the solution became less accurate with increased Reynolds number. Bouhairie and Chup [5] investigated the heat transfer from the surface of a circular cylinder into a crossflow using a two-dimensional model, for a range of Reynolds numbers from $R e=$ 200 to 15 550. The results showed that the two-dimensional model captured the unsteady processes and produced results that were consistent with the available experimental data. It provided relatively correct overall results, the front stagnation and the back-to-total heat-transfer rates. Patnana et al. [6] studied forced convection heat transfer characteristics of a cylinder immersed a in streaming power-law fluid in the two-dimensional (2-D), unsteady flow regime. Based on their research, the Nusselt number increased with increasing values of the Reynolds or Prandtl numbers, irrespective of the value of the flow behavior index. Khan et al. [7] used the Karman-Pohlhausen method to investigate fluid flow around and heat 
transfer from an infinite circular cylinder. The results for both drag and heat transfer coefficients were in good agreement with experimental/numerical data for a circular cylinder.

Huang et al. [9] displayed time-averaged topological flow patterns and their influence on vortex shedding of a square cylinder in cross flow at incidence. In contrast to the circular cylinder, at the critical incidence angle the wake width and shear-layer turbulence present minimum values. Ng et al. [12] investigated the wakes behind cylinders having an equilateral triangular cross-section numerically for various cylinder inclinations and Reynolds numbers. It was found that phase trajectories of the force coefficients revealed that the transition from the bi-layered wake to the $2 \mathrm{P}$-like wake altered the profile significantly, while the transitions to the other observed vortex streets did not incur such changes.

When such devices with two cylinders are designed, it is essential to understand the effects of interference among adjacent wakes on heat transfer characteristics to achieve high efficiency. Generally, forced convective heat transfer on two nearby isothermal circular cylinders of equal diameter immersed in crossflow would be the simplest model with wake interaction [13-19]. Buyruk [14] numerically studied convective heat transfer in the presence of multiple circular cylinders in a staggered arrangement as well as in tandem in the laminar flow regime. Carmo and Meneghini [15] investigated the incompressible flow around pairs of circular cylinders in tandem arrangements by the spectral element method. It was found that, for $R e>190$, when three-dimensional structures are present in the flow field, two-dimensional simulations are not sufficient to predict the pair of drag inversion. Juncu [16] presented a computational study of the forced convection heat transfer around two circular cylinders in tandem arrangement using the finite difference method. Unsteady laminar convective heat transfer from two isothermal cylinders in tandem arrangement was numerically investigated by Mahir and Altac [17]. It was found that the mean Nusselt number of the upstream cylinder approached to that of a single isothermal cylinder for $L / D>4$ and 
the mean Nusselt number of the downstream cylinder was about $80 \%$ of the upstream cylinder.

Besides the tandem arrangement, much research work concerned two cylinders in staggered arrangements [20-23]. Beale and Spalding [20] conducted a numerical study of unsteady fluid flow for in-line and staggered tube banks. Calculated Strouhal numbers were in fair agreement with experimental data. For the staggered geometry, they found the values are between 0.26 and 0.35, a little higher than measured values. Summer [21] considered the flow pattern for two staggered circular cylinders in cross-flow using flow visualization and particle image velocimetry. Han et al. [22] presented heat transfer on two nearby isothermal circular cylinders of equal diameter immersed in a uniform crossflow at $R e=120$ and $P r=$ 0.7 numerically. It turned out that significant changes in the characteristics of heat transfer were noticed depending on how they are positioned, resulting in quantitative changes in heat transfer coefficients of both cylinders. Some papers [24, 25] began to paid attention to jet crossflow heat transfer on a circular cylinder, because a circular impinging jet on a flat plate served as a fundamental configuration among others. Saghafian [26] conducted a study of steady incident flow past a circular cylinder for sub- to supercritical Reynolds numbers by considering an unsteady Reynolds-averaged Navier-Stokes (RANS) formation with nonlinear eddy-viscosity modelling. Recently, cylinder, as a structure component, is used in many fields [27-29]. A Numerical analysis of heat transfer and flow field around cross-flow heat exchanger tube with fouling was conducted by Vessakosol and Charoensuk [27]. They found that the heat transfer rate of cross-flow heat exchanger depends on the eccentricity and thermal conductivity ratio between the fouling material and fluid. Chen et al. [28] concentrated on the three-dimensional vortex flow near the endwall with a short cylinder in the crossflow. From their research, the step-induced vortices interacted with the separated shear layer and horseshoe vortices by using stepped-diameter circular cylinder. 
Oscillating flow is a relatively new technique of heat transfer enhancement applied in many fields, such as jet impingement cooling [30]. It is known that a vortex street is generated when a flow is passing a cylinder. Besides forced mixing by the vortex street, extra imposed oscillating incoming flows are considered in the present study. Unsteady laminar convective heat transfer past two cylinders in tandem arrangement is numerically investigated. The flow parameters, such as the lift and drag coefficients and Strouhal number of a single cylinder at different Reynolds numbers are also provided to validate the calculation procedure by comparing with previous experiments. Different frequencies and amplitudes of the oscillating flows are applied as inlet boundary conditions in the crossflow of two cylinders. The objective of this work is to investigate interactions between the imposed oscillating flow and inherent vortex streets, and then enhance the convective heat transfer of two cylinders in crossflow.

\section{Governing Equations and Boundary Conditions}

The governing equations used for unsteady and incompressible viscous flow are shown below.

Continuity equation

$$
\frac{\partial u}{\partial x}+\frac{\partial v}{\partial y}=0
$$

Momentum equations

$$
\begin{aligned}
& \frac{\partial u}{\partial t}+u \frac{\partial u}{\partial x}+v \frac{\partial u}{\partial y}=-\frac{1}{\rho} \frac{\partial p}{\partial x}+v\left(\frac{\partial^{2} u}{\partial x^{2}}+\frac{\partial^{2} u}{\partial y^{2}}\right) \\
& \frac{\partial v}{\partial t}+u \frac{\partial v}{\partial x}+v \frac{\partial v}{\partial y}=-\frac{1}{\rho} \frac{\partial p}{\partial y}+v\left(\frac{\partial^{2} v}{\partial x^{2}}+\frac{\partial^{2} v}{\partial y^{2}}\right)
\end{aligned}
$$

Energy equation

$$
\frac{\partial T}{\partial t}+u \frac{\partial T}{\partial x}+v \frac{\partial T}{\partial y}=\alpha\left(\frac{\partial^{2} T}{\partial x^{2}}+\frac{\partial^{2} T}{\partial y^{2}}\right)
$$


where $u$ and $v$ are the velocity components in the $x$-direction and y-direction, respectively $p$ the pressure, $v$ the kinematic viscosity, $\rho$ the density, and $T$ the temperature of the fluid. $\alpha$ is the thermal diffusivity, defined as $k / \rho c_{\mathrm{p}}$, where $k$ is the thermal conductivity and $c_{\mathrm{p}}$ is the specific heat of the fluid.

Figure 1 explicitly shows the computational domain for one or two cylinders. For the computational domain of one cylinder, the length of the domain is $30 D$ and the width is $20 D$. The cylinder is located at the front of the computational domain at a distance of 10D from the inlet. $D$ is the diameter of the cylinder. For the computational domain of two cylinders, the length of the domain is $35 D$ and the width is $20 D$. The distance between the two cylinders is placed $5 D$ and the first cylinder is $10 D$ downstream of the inlet.

For the calculation the crossflow of two cylinders, a constant temperature $T_{\mathrm{w}}$ is applied on the cylinder walls. No-slip velocity conditions are applied on the sidewalls. At the inlet, inlet velocity related to Reynolds number is set and the uniform fluid temperature is $T_{\infty}$. The outflow conditions are chosen for the outlet. Air is chosen as the coolant in the computational domain.

For the inlet flow with constant velocity, one has

At the inlet, $u=U_{\infty}, T=T_{\infty}$;

At the outlet, $\frac{\partial u}{\partial x}=0, \frac{\partial v}{\partial x}=0, \frac{\partial T}{\partial x}=0$;

At the sidewalls, adiabatic wall, $u=0, v=0$;

On the cylinder walls, $u=0, v=0, T=T_{w}$;

It is noted that in the calculation validation part, such as the computational domain with one cylinder, the sidewall condition depends on that in previous experiments or calculations. Accordingly, $u=0, v=0$ or $u=U_{\infty}, v=0$ are both used for the sidewalls.

In order to investigate the interaction between the imposed oscillating flow and inherent vortex streets, oscillating inlet flows are set at the inlet. The inlet velocity profile is varied sinusoidally. The cycle ratios of the oscillating inlet flows, $T_{\text {inlet }} / T_{\text {vortex }}$, are defined by the 
cycle of oscillating inlet flows divided by the cycle of vortex streets at constant inlet velocity $v_{\text {avg. }} T_{\text {vortex }}$ is constant for all the cases, and is obtained at a constant inlet velocity $v_{\text {avg. }} v_{\text {avg }}$ is the average velocity of the oscillating inlet flows. $T_{\text {vortex }}$ is $1.20 \mathrm{~s}$ in the study. It ranges from $0.50 \sim 1.05$, and is increased in steps by 0.05 for every case. Similarly, the amplitude ratio $\mathrm{a} / v_{\text {avg }}$ is set at $0.25,0.50,0.75,1.00$. $v_{\text {avg }}$ is set as constant for all the cases and $a$ represents the varying amplitude of the oscillating inlet flow. The oscillating inlet flow changes in a sinusoidal function and is schematically displayed in Fig. 2.

The lift coefficient $C_{\mathrm{L}}$ and drag coefficient $C_{\mathrm{D}}$ are defined as:

$$
C_{D}=\frac{2 F_{x}}{\rho D U_{\infty}^{2}}, \quad C_{L}=\frac{2 F_{y}}{\rho D U_{\infty}^{2}}
$$

where $\rho$ is the density of the fluid, $D$ is the diameter of the cylinder and $F_{x}, F_{\mathrm{y}}$ are the force components in the $x, y$ direction, respectively.

The vortex shedding frequencies are obtained from the Fast Fourier Transform (FFT) of the $C_{\mathrm{L}}$ history curve versus time. The Strouhal number, which is a non-dimensional measure of the oscillating flow, is defined as follows:

$$
S t=f D / U_{\infty}
$$

where $f$ is the frequency of the vortex streets provided by FFT.

The Reynolds number in the present research is defined as $R e=U_{\infty} \mathrm{D} / v$, where $v$ is the kinematic viscosity, $D$ is the diameter of the cylinder. The local heat transfer coefficient and local Nusselt number can be calculated from,

$$
-\left.k \frac{\partial T}{\partial n}\right|_{\mathrm{w}}=h_{\theta}, \quad N u_{\theta}=\frac{h_{\theta} D}{k}
$$

where $n$ is the direction normal to the cylindrical curve; $\theta$ is the polar angle relative to the cylinder center, $h_{\theta}$ and $N u_{\theta}$ means the local heat transfer coefficient and local Nusselt number, respectively. For unsteady simulations, each local heat transfer coefficients and local Nusselt numbers are the averaged values for several cycles. The averaged Nusselt number is then 
calculated as follows:

$$
N u_{\text {avg }}=\frac{1}{2 \pi} \int_{0}^{2 \pi} N u_{\theta} d \theta
$$

\section{Verification of Numerical Method}

In the present study, unsteady laminar convective heat transfer past two cylinders in tandem arrangement is numerically investigated. The computations are conducted by the simulation software FLUENT, version 14.5. FLUENT uses the finite volume method to solve the governing equations of fluid flow and heat transfer. The Semi-Implicit Method for Pressure Linked Equations (SIMPLE) algorithm is selected to handle the coupling between pressure and velocities. The momentum and energy equations are discretized by the second order upwind scheme. Second order implicit scheme is chosen for the discretization of transient items. The commercial software, ICEM CFD, version 14.5 is used to create the geometric models and generate the structured meshes.

To verify the numerical calculations, three mesh systems with different mesh densities based on one cylinder computational domain are generated. The heights of the boundary layer are respectively $y / D=0.01, y / D=0.075, y / D=0.005$ and $y / D=0.001$ and the growth ratio is set as 1.01 for all cases. The designed mesh systems are displayed in Fig. 3. For the mesh system with $y / D=0.01$, a vortex street cannot be found for the calculations at $R e=200$. However, the vortex street can be found in the mesh system of $y / D=0.005$. Comparisons of calculated results obtained by the four mesh systems at $\mathrm{Re}=200$ are shown in Table 1 . When the mesh size of the boundary layer becomes smaller than $y / D=0.005$, the results show no obvious variations. The mesh system with $y / D=0.005$ has provided enough accuracy for calculations. Accordingly, the mesh system with $y / D=0.005$ is used for further verifications. Based on the computational domain with one cylinder, Figure 4 presents the comparison of the numerical results with the experimental data by Schlichting [31]. From the figure, the 
drag coefficient and Strouhal number have good agreements with the experimental data in the computational domain for a single cylinder. In addition, the comparisons of the averaged Nusselt number distributions along the cylinder surface with the previous literature and experiment [22, 32] are shown in Figure 5. The results are obtained at $R e=120$ in a single cylinder computational domain. The calculated results show a good agreement with the previous experiment and calculation.

The mean Nusselt number of a single cylinder in the crossflow in two-dimensional domain is also compared with previous correlations in the literature:

Knudsen and Katz [33]

$$
N u=0.683 \operatorname{Re}^{0.466} \operatorname{Pr}^{1 / 3}
$$

Churchill and Bernstein [34]

$$
N u=0.3+\frac{0.62 \operatorname{Re}^{1 / 2} \operatorname{Pr}^{1 / 3}}{\left[1+(0.4 / \mathrm{Pr})^{2 / 3}\right]^{1 / 4}}\left[1+\left(\frac{\mathrm{Re}}{282000}\right)^{5 / 8}\right]^{4 / 5}
$$

The comparison is showed in Table 2. From the table, the calculated result agrees very well with the predictions of the two correlations in Ref. [33. 34].

Based on the numerical verification, the mesh system with $y / D=0.005$ is deemed reasonable to be used. For the mesh system with $y / D=0.001$, it need large amounts of computation resources. Considering the computation power and calculation accuracy, so the mesh system with $y / D=0.005$ is adopted. For the two cylinder cases, it contains about 121,000 quadrilateral cells.

The Strouhal number and lift coefficient are computed and compared with available numerical data and experimental data. For one fluctuating cycle of the lift coefficient, there should be 20-25 sampling points to conjecture the outline of the fluctuation trend of the lift stress. At $R e=200$, the time step $\Delta t=0.01 \mathrm{~s}$ is adopted in this study. For every time step, the maximum number of iteration is set to 200. The minimum convergence error criterion for the continuity equation, momentum equations and energy equation is $10^{-4}$. For a typical case, it 
takes about 48 hours to obtain the required computational accuracy with 16 CPUs' parallel calculations and $32 \mathrm{G}$ storages.

As preparation of the oscillating inlet flow, the computational domain with two cylinders at constant inlet flow rate is built for comparisons. The constant inlet flow rate is applied in the computational domain for $R e=200$. No-slip wall boundary condition is chosen for the side walls in the computations.

For the two cylinders in present calculation, the Nusselt number are, respectively, $N u_{\text {cylinder } 1}=7.54, N u_{\text {cylinder2 }}=6.52$. Based on the calculations, the Nusselt number of the first cylinder is a little increased and that of the second cylinder is decreased, which is consistent with Ref. [17]. The Nusselt number comparisons of the two cylinders with Ref. [17] are shown in Table 3. The values in the present research is a little larger is due to no-slip wall boundary condition used in the computational domain with two cylinders which will increase the flow velocity around the cylinders. According to the investigation [35] by Zdravkovich, there are three major flow regimes observed in the crossflow of two tandem cylinders. In the co-shedding regime, $L / D$ should be larger than 4 in the two-dimensional computational domain. In the present study, the $L / D$ is set to 5 to ensure that the crossflow of two tandem cylinders in the co-shedding flow regime.

\section{Results and Discussion}

The oscillating inlet flows are set at the inlet to investigate the interaction between the imposed oscillating flow and the inherent vortex streets. The cycles of the oscillating inlet flows are provided by the form of cycle ratio $T_{\text {inlet }} / T_{\text {vortex. }}$ In the present research, $T_{\text {inlet }} / T_{\text {vortex }}$ ranges from $0.5 \sim 1.05$, increasing by 0.05 for every case, so twelve cases are included for investigating the effect of the cycle ratio. The Nusselt numbers and the corresponding enhancements of the upstream cylinder and the downstream cylinder at $\operatorname{Re}=200$ are shown

in Table 4, respectively. The Nusselt numbers are obtained by averaging a large amount of 
Nusselt numbers of different cycles after the unsteady simulations became stable. The statistic time for averaging is more than 3000 time steps for every case. The Nusselt number enhancement is based on the comparison with the case with constant inlet velocity. Generally speaking, the Nusselt numbers of the upstream cylinder and the downstream cylinder are increased when the oscillating inlet flow is applied. The cycle ratio also has a great effect on the Nusselt number of the upstream cylinder and the downstream cylinder. For the upstream cylinder, when the cycle ratio is close to 0.90 , the heat transfer enhancement is a little larger. For the downstream cylinder, the trend is more complex. The heat transfer enhancement is larger when the cycle ratio is close to 0.50 or 0.90 . The difference for the downstream cylinder may be due to the effect of the vortex street generated by the upstream cylinder which changes the cycle of the vortex street of the downstream cylinder. The Nusselt numbers of two cylinders with oscillating inlet flows versus different cycle ratios are shown in Figure 6. The heat transfer enhancement in the case with oscillating inlet flows is more obviously presented in this figure. For the upstream cylinder, the peak point occurs at the cycle ratio of 0.85 or 0.90 . The heat transfer of the downstream cylinder is a combination of the vortex street of the upstream cylinder and the imposed oscillating flows. For the downstream cylinder, the peak points are located at the cycle ratios of 0.9 and 0.5 . The lowest point appears close to the cycle ratio of 0.75 .

The effect of the amplitude ratio is also tested at $R e=200$ in this research. At two specified cycle ratios 0.90 and 1.00 , the amplitude ratio $a / v_{\text {avg }}$ is set as $0.25,0.50,0.75$ and 1.00, respectively, where $v_{\text {avg }}$ is constant for all the cases. The Nusselt numbers of the upstream cylinder and the downstream cylinder versus different amplitudes are shown in Table 5. At the two specified cycle ratios, the Nusselt numbers of the two cylinders are both increased with increased amplitude ratios. At the largest amplitude ratio 1.00, the heat transfer enhancement can reach as high as $20 \%$. It is concluded that the larger amplitude ratio 
of the inlet oscillating flow can efficiently elevate the heat transfer of the two cylinders. The Nusselt numbers of two cylinders in the computational domain with oscillating inlet flow versus different amplitude ratios at $R e=200$ are shown in Figure 7. It is clearly shown that the heat transfer of two cylinders is increased with the amplitude ratios, consistent with the conclusion above.

The vorticity magnitude contours and vectors around two cylinders with different cycle ratios at $R e=200$ and $a / v_{\text {avg }}=0.25$ are shown in Fig. 8. From this figure, the vortex street is obviously different for the cases at different cycle ratios. For a constant inlet flow, the flow pattern is the normal vortex street. For the oscillating inlet flow, the vortex street becomes non-regular and presents different shapes. In addition, for the oscillating inlet flow, the vortex street expands and vibrates in a larger region which means stronger flow mixing. The strong flow mixing contributes to larger heat transfer compared with the case with constant inlet flow.

Figure 9 presents the vorticity magnitude contours and vectors around two cylinders with different amplitude ratios at $R e=200$ and $T_{\text {inlet }} / T_{\text {vortex }}=0.90$. The vortex becomes more non-regular and is spread out in a wider region. With increased amplitude ratios, the vortex fluctuates in a larger region and results in a stronger flow mixing. Then the heat transfer around two cylinders is largely enhanced. As $a / v_{\text {avg }}$ reaches 1.00 , the vortex street becomes so different from the normal vortex street and the vortex presents different shapes. The oscillating inlet flow elongates the vortex shapes and sometimes breaks up the vortex into two parts.

The transient Nusselt number distributions along the two cylinders for the cases with different cycle ratios at $R e=200$ and $a / v_{\text {avg }}=0.25$ are presented in Figure 10 . The distribution is from the upstream and along the anticlockwise direction of the cylinder, as shown in the left side of the figure. Three cases with different cycle ratios are considered and the case with 
constant inlet velocity is also included for comparison. For the upstream cylinder, the Nusselt number distributions are similar for all the cases with different cycle ratios. The only difference is that the Nusselt number of the upstream cylinder is larger in the case with $T_{\text {inlet }} /$ $T_{\text {vortex }}=0.90$ compared with the other cases. For the downstream cylinder, the Nusselt number distribution is so different from that of the upstream cylinder. In addition, the cycle ratio also has a great effect on the distributions of Nusselt number and the distributions are different for the cases with different cycle ratios. Figure 11 displays the transient Nusselt number distributions along the two cylinders for the cases with different amplitude ratios at $R e=200$ and $T_{\text {inlet }} / T_{\text {vortex }}$ is set as 0.90 . Both the Nusselt number distributions of the upstream cylinder and the downstream cylinder are influenced by the change of the oscillating inlet flow amplitudes. It is obvious that the Nusselt number is increased with the increased the amplitude of the oscillating inlet flow.

Figure 12 shows the time-averaged Nusselt number distributions along two cylinders for the cases with different cycle ratios at $R e=200$ and $a / v_{\text {avg }}=0.25$. For the time-averaged distribution, the Nusselt number distribution is symmetric along the centerline for both the upstream cylinder and the downstream cylinder. The Nusselt number distributions of the upstream cylinder are similar for all the cases, also consistent with previous research works. The lowest heat transfer is not at the downstream side and there is a small peak at the downstream side of the upstream cylinder. For all the cases, the Nusselt numbers of the upstream cylinder and the downstream cylinder are both slightly elevated compared with the case of a constant inlet flow.

The Nusselt number distributions along the two cylinders for the cases with different amplitude ratios at $R e=200$ are presented in Figure 13. The cycle ratios are controlled as $T_{\text {inlet }} / T_{\text {vortex }}=0.92$ and $T_{\text {inlet }} / T_{\text {vortex }}=1.00$ for the variance of amplitude ratios. With the increased amplitude ratios, the heat transfer of the two cylinders is enhanced from the figure. 
For the cycle ratio $T_{\text {inlet }} / T_{\text {vortex }}=1.00$, the heat transfer peak at the centerline becomes larger. However, for the cases with $T_{\text {inlet }} / T_{\text {vortex }}=0.90$, the heat transfer distribution becomes asymmetric with increased amplitude ratios. Nevertheless, it can be obviously observed clearly that the heat transfer of two cylinders is greatly enhanced by the increased amplitude ratios. The asymmetric distribution is a combination of oscillating inlet flow and the naturally vortex street at larger amplitude ratios. From the figure, it is obvious that the heat transfer peak at the downstream side of the upstream cylinder is weakened at high amplitude ratios when $T_{\text {inlet }} / T_{\text {vortex }}$ is set as 0.90 .

\section{Summary and Conclusions}

Unsteady laminar convective heat transfer and fluid flow past two cylinders in tandem arrangement was numerically investigated in the present research work. Crossflow around a single cylinder is considered to validate the numerical calculations. Besides forced mixing by the natural vortex street, extra imposed oscillating inlet flow was also considered in the present study to investigate the interaction of two kinds of oscillating flows. The calculation of crossflow around two cylinders with constant inlet flow was provided as the base line for applying oscillating inlet flows. For the cycle effect, the cycles of the oscillating inlet flows were defined by the form of a cycle ratio $T_{\text {inlet }} / T_{\text {vortex }}$, with $T_{\text {inlet }} / T_{\text {vortex }}$ ranging from $0.5 \sim 1.05$, increasing in steps by 0.05 for every case at the specified amplitude ratio. For the amplitude effect, the amplitudes ratio $a / v_{\text {avg }}$ was defined and set as $0.25,0.50,0.75$ and 1.00, respectively, at two specified cycle ratios, 0.90 and 1.00 . The conclusions emerged from this study are:

(1) The crossflow of two tandem cylinders belongs to the co-shedding flow regime and the heat transfer of the downstream cylinder is affected by both the natural vortex street and the imposed oscillating flow. 
(2) For the cycle effect, the heat transfer enhancement of the upstream cylinder and the downstream cylinder are larger by combined of the natural vortex streets and the imposed oscillating inlet flows. The interaction between the natural vortex street and the imposed oscillating inlet flow leads to the appearance of the non-regular vortex streets and differently shaped vortices with increased flow mixing.

(3) Nusselt numbers of the two cylinders are both increased greatly with the increased amplitude ratio. With increased amplitude ratio, the vortex street expands and vibrates in a larger region and produces stronger flow mixing which benefits the heat transfer around the cylinders. The stronger flow mixing leads to higher heat transfer without increasing the flow rate of the coolant flow. At the amplitude ratio 1.00, the heat transfer enhancement can reach as high as $20 \%$.

(4) Generally, an oscillating inlet flow can efficiently increase the heat transfer of two cylinders without increasing the flow rate of the coolant. Because an oscillating inlet flow is common in engineering, e.g., synthetic jet in electronic cooling, oscillating inlet flow might be an efficient cooling method in the future energy systems.

\section{Acknowledgments}

This work has been carried out at the School of Marine Science and Technology, Northwestern Polytechnical University, Xi'an, China and the Department of Energy Sciences at Lund University, Sweden. The research work is financially supported by the China Scholarship Council (CSC) and Swedish Energy Agency. The corresponding author Prof. Gongnan Xie wishes to thank the National Natural Science Foundation of China (51676163) and the Fundamental Research Funds of Shaanxi Province (2015KJXX-12). 


\section{References}

[1] E. Buyruk, M.W. Johnson, I. Owen, Numerical and experimental study of flow and heat transfer around a tube in cross-flow at low Reynolds number, Int. J. Heat Fluid Flow 19 (1998) 223-232.

[2] F. S. Hover, A.H. Techet, M.S. Triantafyllou, Forces on oscillating uniform and tapered cylinders in crossflow, J. Fluid Mech. 363 (2007) 97-114.

[3] J. Franke, W. Frank, Large eddy simulation of the flow past a circular cylinder at $\operatorname{Re}_{D}=3900, J$. Wind Engineering 90 (2002) 1191-1206.

[4] P. Catalano, M. Wang, G. Iaccarino, P. Moin, Numerical simulation of the flow around a circular cylinder at high Reynolds numbers, Int. J. Heat Fluid Flow 24 (2003) 463-469.

[5] S. Bouhairie, V.H. Chu, Two-dimensional simulation of unsteady heat transfer from a circular cylinder in crossflow, J. Fluid Mech. 570 (2007) 177-215.

[6] V.K. Patnana, R.P. Bharti, R.P. Chhabra, Two-dimensional unsteady forced convection heat transfer in power-law fluids from a cylinder, Int. J. Heat Mass Transfer 53 (2010) 4152-4167.

[7] W.A. Khan, J.R. Culham, M.M. Yovanovich, Fluid flow around and heat transfer from an infinite circular cylinder, ASME J. Heat Transfer 127 (2005) 785-790.

[8] R. Golani, A.K. Dhiman, Fluid flow and heat transfer across a circular cylinder in the unsteady flow regime, Int. J. Engineering Science 3 (2014) 08-19.

[9] R.F. Huang, B.H. Lin, S.C. Yen, Time-averaged topological flow patterns and their influence on vortex shedding of a square cylinder in crossflow at incidence, J. Fluids Structures 26 (2010) 406-429.

[10] M. Zhao, L. Cheng, L. Liu, Vortex induced vibrations of a rotating circular cylinder at low Reynolds number, Physics of Fluids 26 (2014) Paper No. 073602. 
[11] O. Zeitoun, Mohamed Ali, A. Nuhait, Convective heat transfer around a triangular cylinder in an air cross flow, Int. J. Thermal Science 50 (2011) 1685-1697.

[12] Z.Y. Ng, T. Vo, W.K. Hussam, G.J. Sheard, Two-dimensional wake dynamics behind cylinders with triangular cross-section under incidence angle variation, J. Fluids Structures 63 (2016) 302-324.

[13] J.R. Meneghini, F. Saltara, C.L.R. Siqueira, J.A. Ferrari, Numerical simulation of flow interference between two circular cylinders in tandem and side-by-side arrangements, $J$. Fluids Structures 15 (2001) 327-350.

[14] E. Buyruk, Numerical study of heat transfer characteristic on tandem cylinders, inline and staggered tube banks in cross-flow of air, Int. Comm. Heat Mass Transfer 29 (2002) 355-366.

[15] B.S. Carmo, J.R. Meneghini, Numerical investigation of the flow around two circular cylinders in tandem, J. Fluids Structures 22 (2006) 979-988.

[16] G. Juncu, A numerical study of momentum and forced convection heat transfer around two tandem circular cylinders at low Reynolds numbers. Part II: Forced convection heat transfer, Int. J. Heat Mass Transfer 50 (2007) 3799-3808.

[17] N. Mahir, Z. Altac, Numerical investigation of convective heat transfer in unsteady flow past two cylinders in tandem arrangements, Int. J. Heat Fluid Flow 29 (2008) 1309-1318.

[18] D. Summer, Two circular cylinders in cross-flow: A review, J. Fluids Structures 26 (2010) 849-899.

[19] A. M. Lavasani, H. Bayat, T. Maarefdoost, Experimental study of convective heat transfer from in-line cam shaped tube bank in crossflow, Applied Thermal Engineering 65 (2014) 85-93.

[20] S. B. Beale, D.B. Spalding, A numerical study of unsteady fluid flow in in-line and staggered tube banks, J. Fluids Structures 13 (1999) 723-754. 
[21] D. Summer, S.J. Price, M.P. Paidoussis, Flow-pattern identification for two staggered circular cylinders in cross-flow, J. Fluid Mech. 411 (2000) 263-303.

[22] T. Han, K.S. Yang, K. Lee, Heat transfer characterization of two isothermal circular cylinders in proximity, ASME J. Heat Transfer 132(2010) 1-4.

[23] B.S. Aghazadeh, Y. M. Sadeghi, An experimental investigation of vortex-induced vibration of a rotating circular cylinder in the crossflow direction, Physics of Fluids 27 (2015) Paper No.067101.

[24] X.L. Wang, D. Motala, T.J. Lu, S.J. Song, T. Kim, Heat transfer of a circular impinging jet on a circular cylinder in crossflow, Int. J. Thermal Science 78 (2014) 1-8.

[25] X.L. Wang, J.H. Lee, T.J. Lu, S.J. Song, T. Kim, A comparative study of single-/two-jet crossflow heat transfer on a circular cylinder, Int. J. Heat Mass Transfer 78 (2014) 588-598.

[26] M. Saghafian, P.K. Stansby, M.S. Saidi, D.D. Apsley, Simulation of turbulent flows around a circular cylinder using nonlinear eddy-viscosity modelling: steady and oscillatory ambient flows, J. Fluids Structures 17 (2003) 1213-1236.

[27] P. Vessakosol, J. Charoensuk, Numerical analysis of heat transfer and flow field around cross-flow heat exchanger tube with fouling, Applied Thermal Engineering 30 (2010) 36-47.

[28] S.B. Chen, S. Sanitjai, K. Ghosh, R.J. Goldstein, Three-dimensional vortex flow near the endwall of a short cylinder in crossflow: Stepped-diameter circular cylinder, Applied Thermal Engineering 40 (2012) 36-47.

[29] S. Rashidi, M. Bovand, J. A. Esfahani, G. Ahmadi, Discrete particle model for convective AL2O3-water nanofluid around a triangular obstacle, Applied Thermal Engineering $\mathbf{1 0 0}$ (2016) 36-47. 
[30] M. Zhang, T.W. Simon, L. Huang, V.B.A. Selvi, M.T. North, T. Cui, A polymeric piezoelectric synthetic jet for electronic cooling, IMECE2011-64392, November 11-17, 2011, Denver, Colorado, USA.

[31] H. Schlichting, Boundary layer Theory, 7th ed. McGraw-Hill, New York, 1979.

[32] E.R.G. Eckert, E. Soehngen, Distribution of heat transfer coefficients around circular cylinders in crossflow at Reynolds numbers From 20 to 500, ASME J. Heat Transfer 74 (1952) 343- 347.

[33] J.D. Knudsen, D.L. Katz, Fluid Dynamics and Heat Transfer, McGraw Hill, 1958, New York.

[34] S.W. Churchill, M.J. Bernstein, A correlating equation for forced convection from gases and liquids to a circular cylinder in crossflow, J. Heat Transfer 99 (1977) 300-306.

[35] M.M. Zdravkovich, Review of flow interference between two circular cylinders in various arrangements, Trans. ASME J. Fluids Eng. 99 (1977) 618-633. 


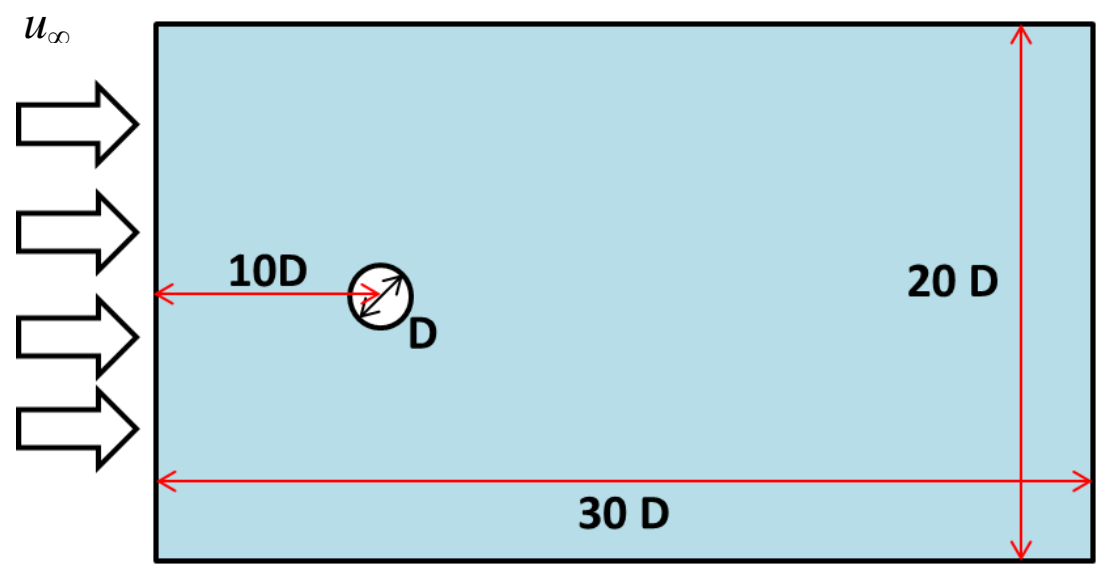

(a) the domain with one cylinder

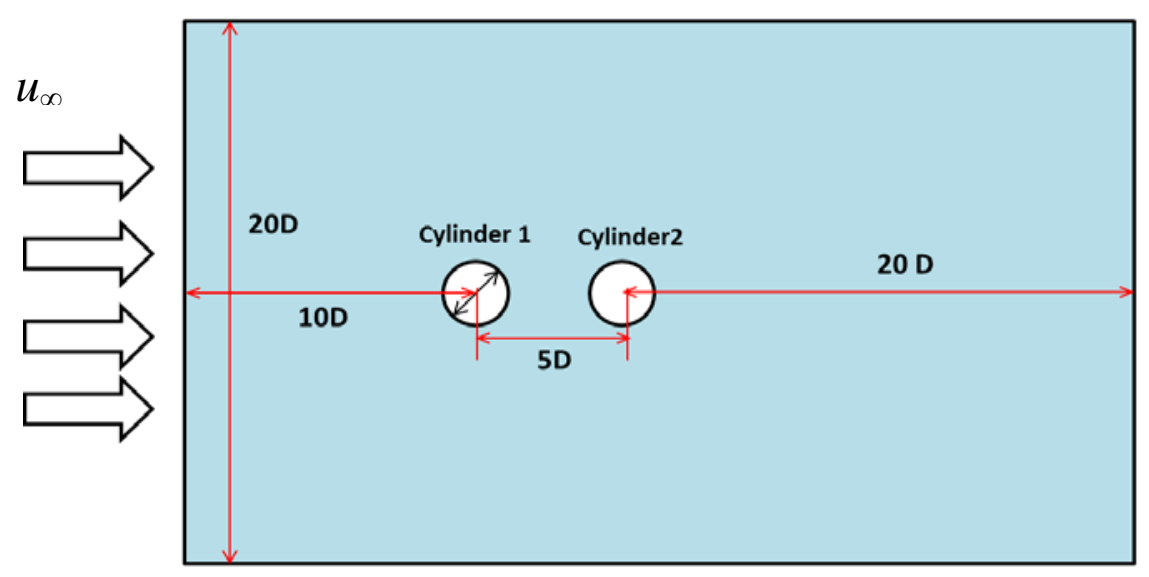

(b) the domain with two cylinders

Figure 1. The schematic configurations of the computational domains, (a) the domain with one cylinder (b) the domain with two cylinders. 
- Frenquencies: $T_{\text {inlet }} / T_{\text {vortex }}=0.5 \sim 1.05$ increasing by 0.05 ;

- Amplitudes: $\mathrm{a} / v_{\text {avg }}=0.25,0.5,0.75,1$;

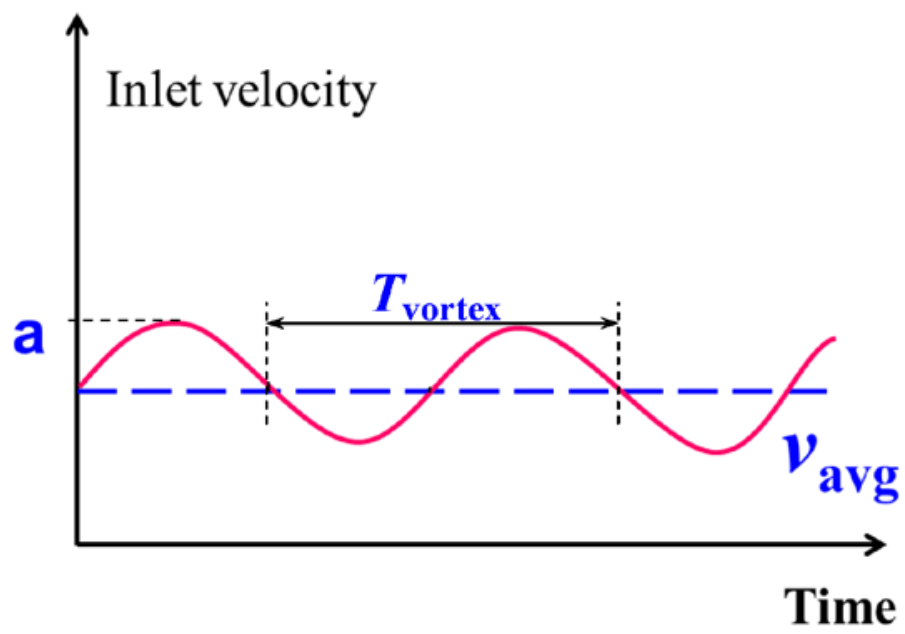

Figure 2. The oscillating inlet flow with different cycle ratios and amplitude ratios 

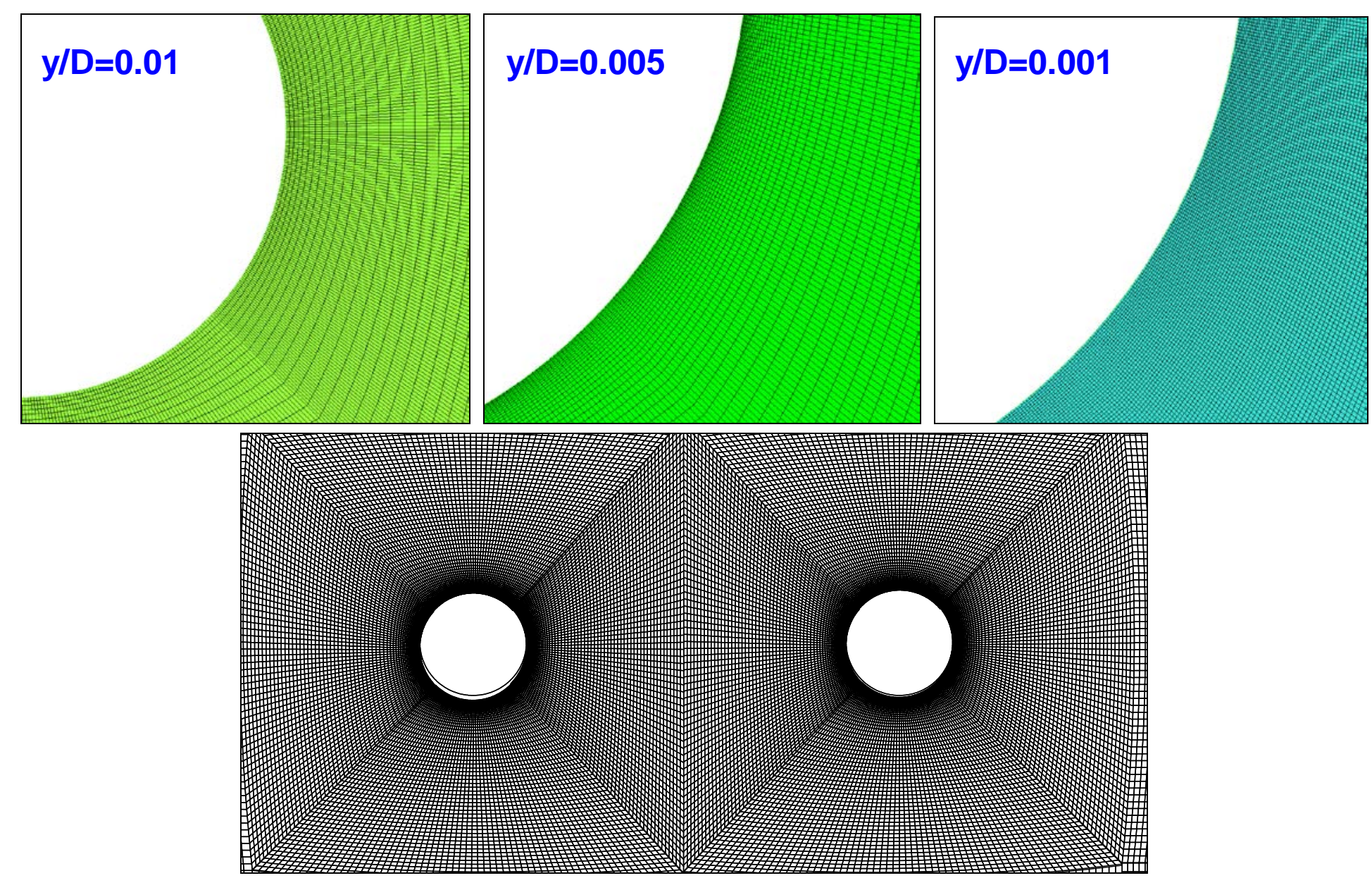

Figure 3. The meshes around a cylinder with different boundary layer heights used for numerical verification and the mesh around two cylinders. $y$ is the height of the mesh at the first layer. The grids around two cylinders are also provided in the figure. 


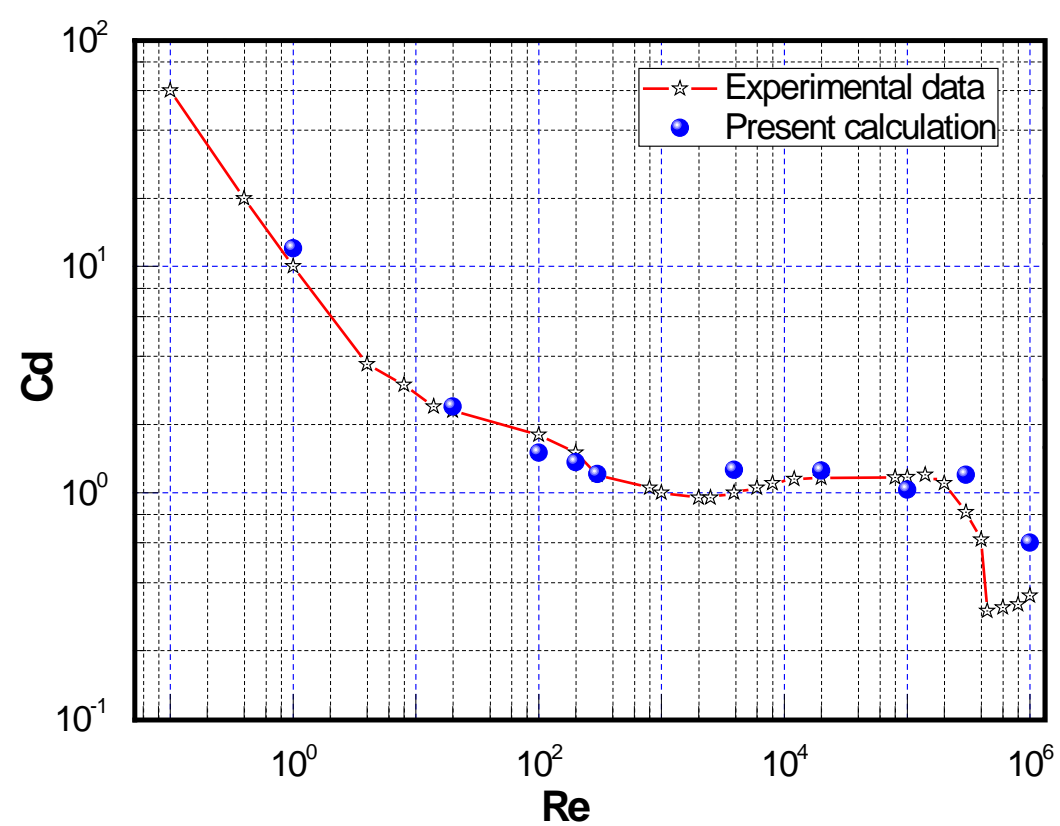

(a) Drag coefficient

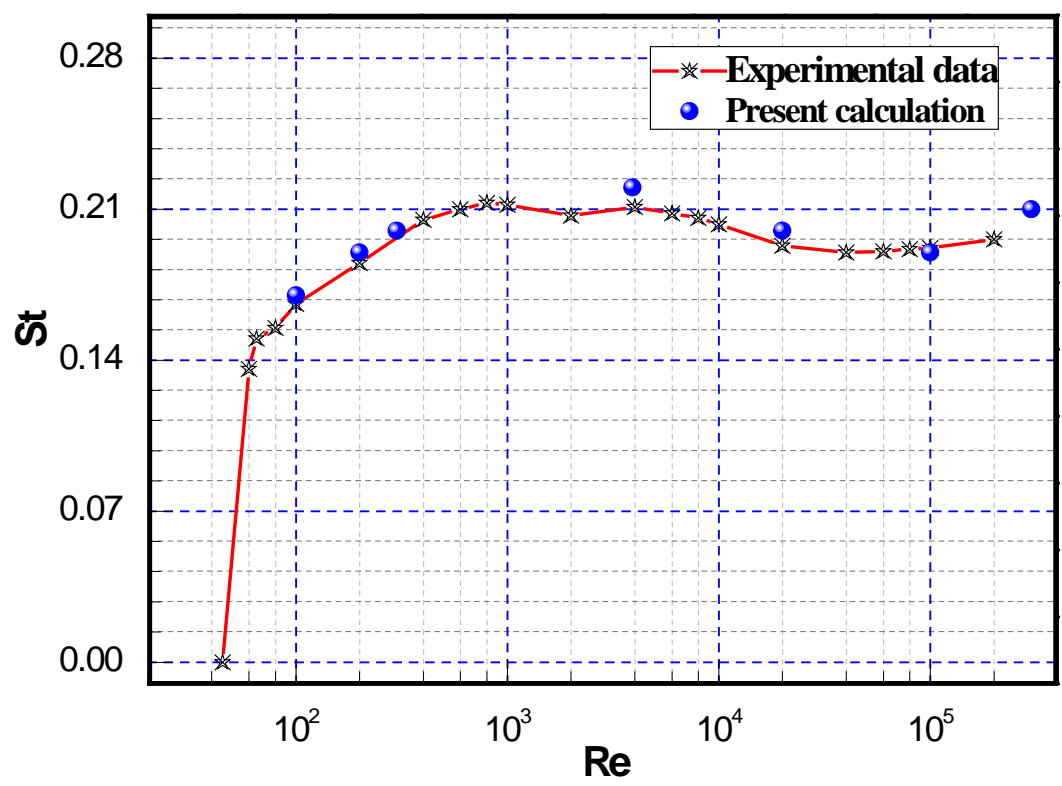

(b) Strouhal number

Figure 4. The comparison of the drag coefficient and Strouhal number with the experimental data from<Boundary layer theory $>$. (a) Drag coefficient; (b) Strouhal number; 


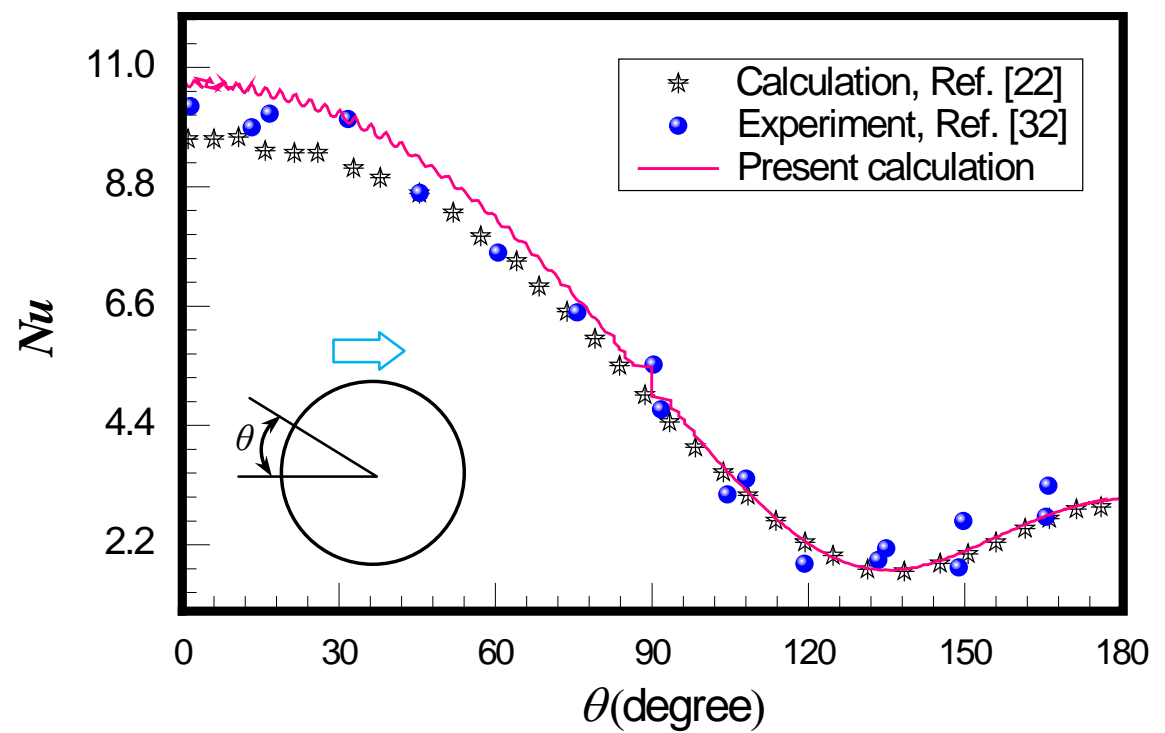

Figure 5. The comparisons of the calculated results with that in previous calculation and experiment. The distribution is the averaged Nusselt number distribution along the cylinder surface at $\operatorname{Re}=120$. 


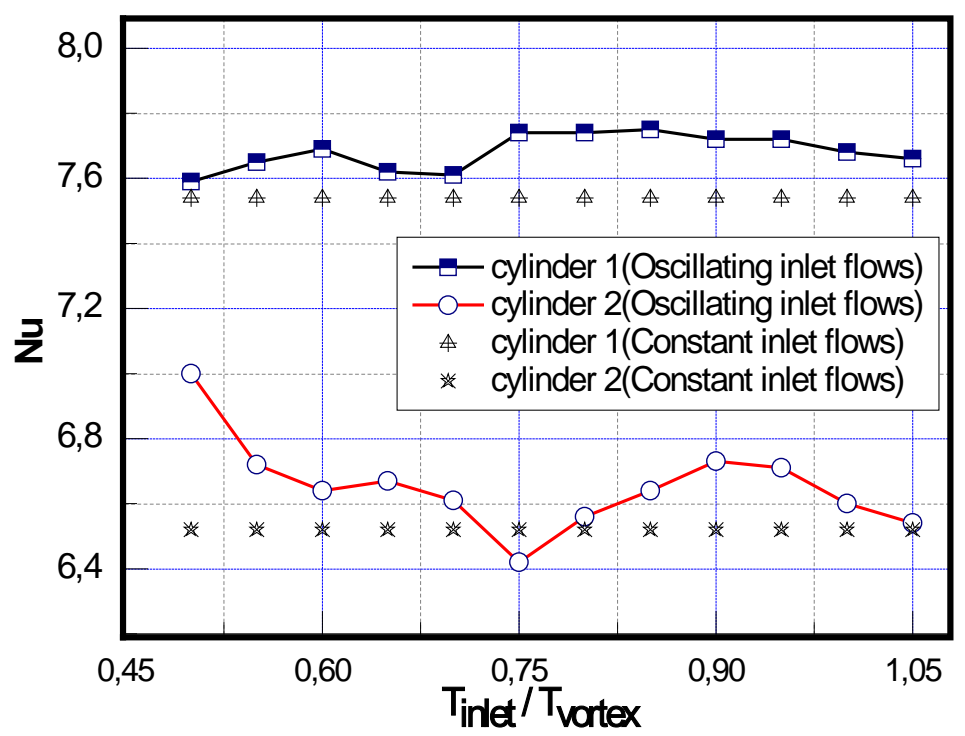

Figure 6. The Nusselt numbers of two cylinders in the computational domain with oscillating inlet flow versus different cycle ratios at $R e=200$. The Nusselt numbers of the case with constant inlet flows are also provided for comparison. The cycle ratio $T_{\text {inlet }} / T_{\text {vortex }}$ ranges from $0.50-1.05$. 

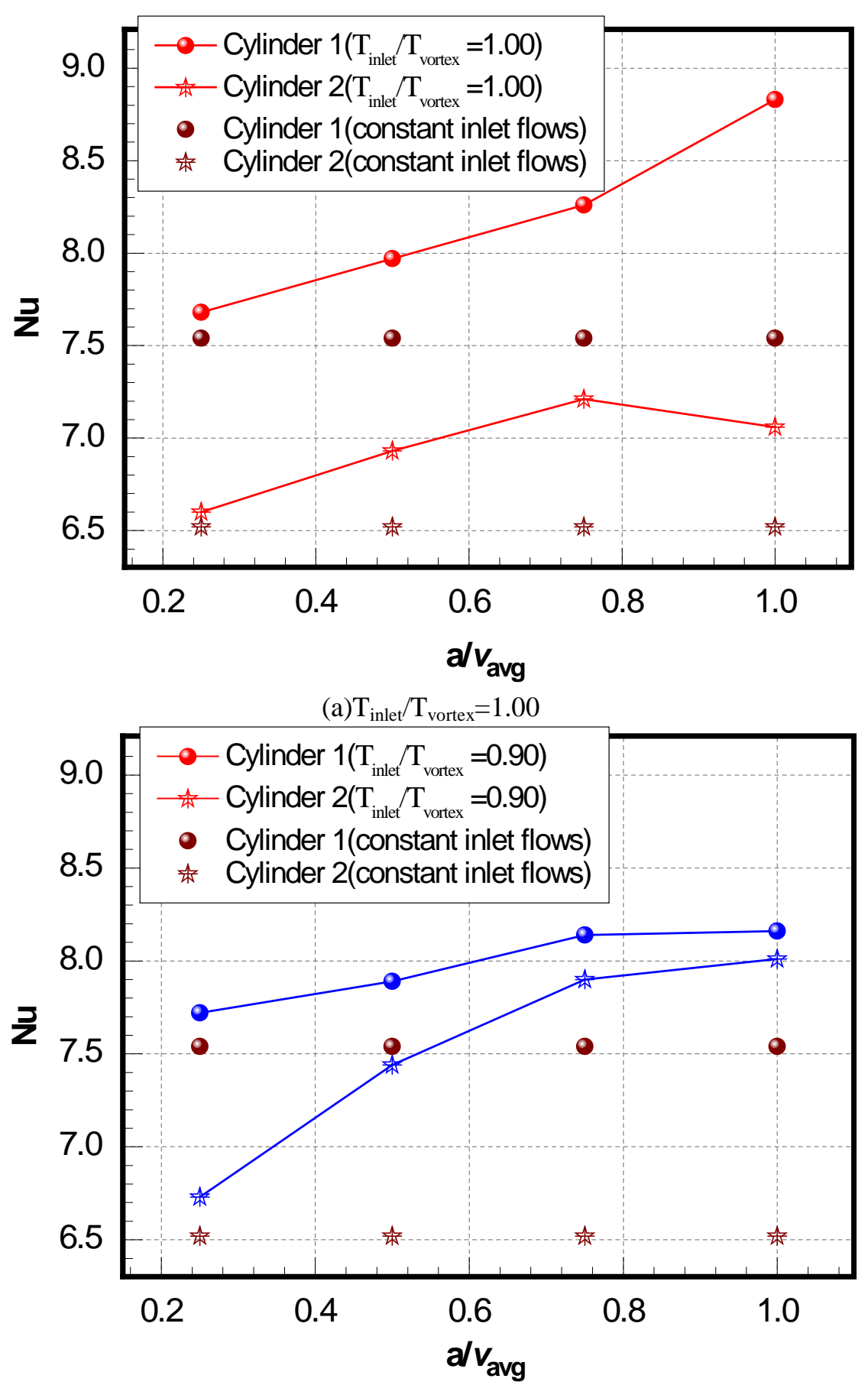

(a) $\mathrm{T}_{\text {inlet }} / \mathrm{T}_{\text {vortex }}=0.90$

Figure 7. The Nusselt numbers of two cylinders in the computational domain with oscillating inlet flows versus different amplitude ratios at $R e=200$. The Nusselt numbers of the case with constant inlet flow are also provided for comparison. The amplitude ratio a / $v_{\text {avg }}$ ranges from 0.25 to 1.00.

(a) $T_{\text {inlet }} / T_{\text {vortex }}=1.00$; (b) $T_{\text {inlet }} / T_{\text {vortex }}=0.90$; 

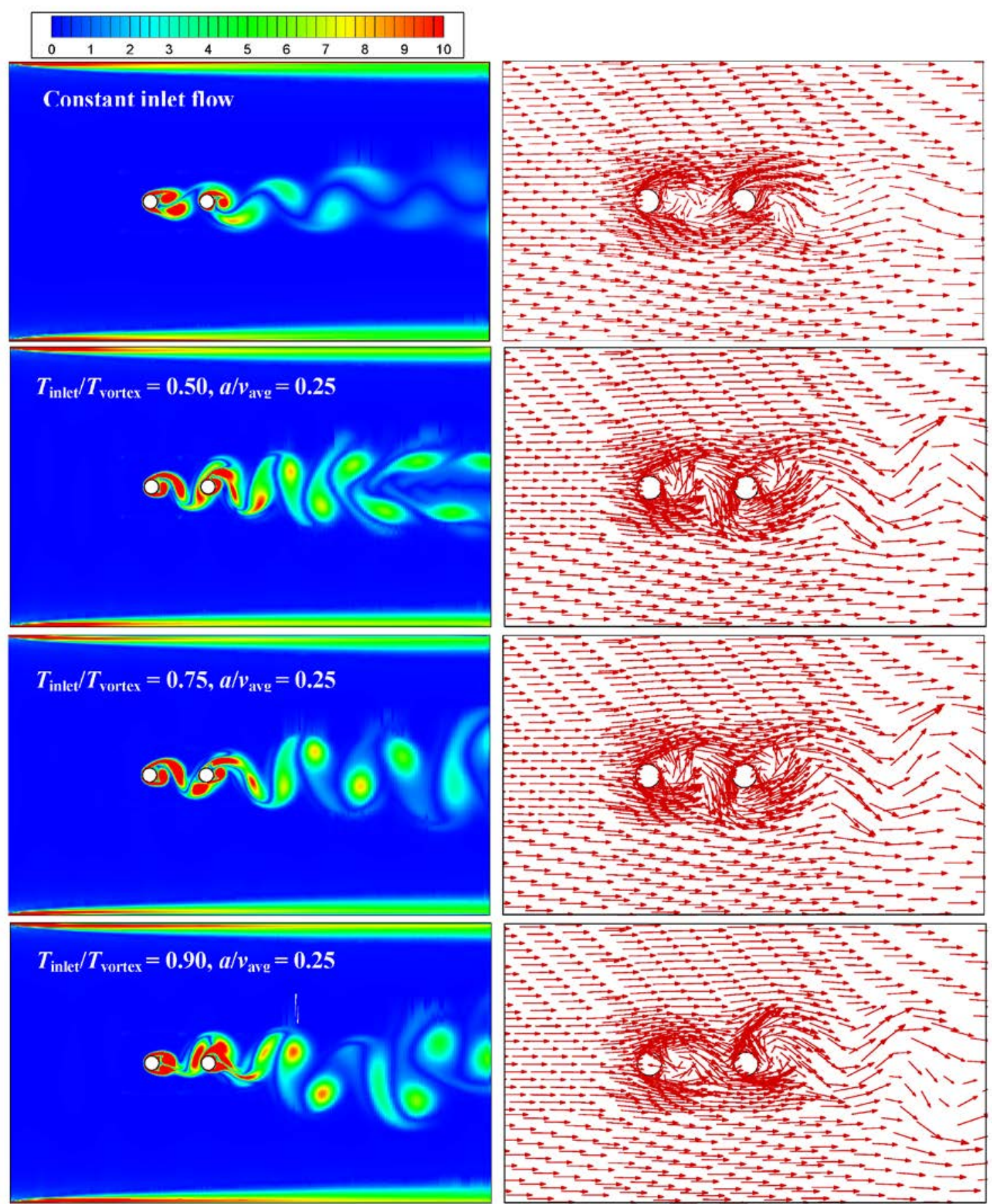

Figure 8. The vorticity magnitude contours and vectors around two cylinders with different cycle ratios at $R e=200$ and $a / v_{\text {avg }}=0.25$. 

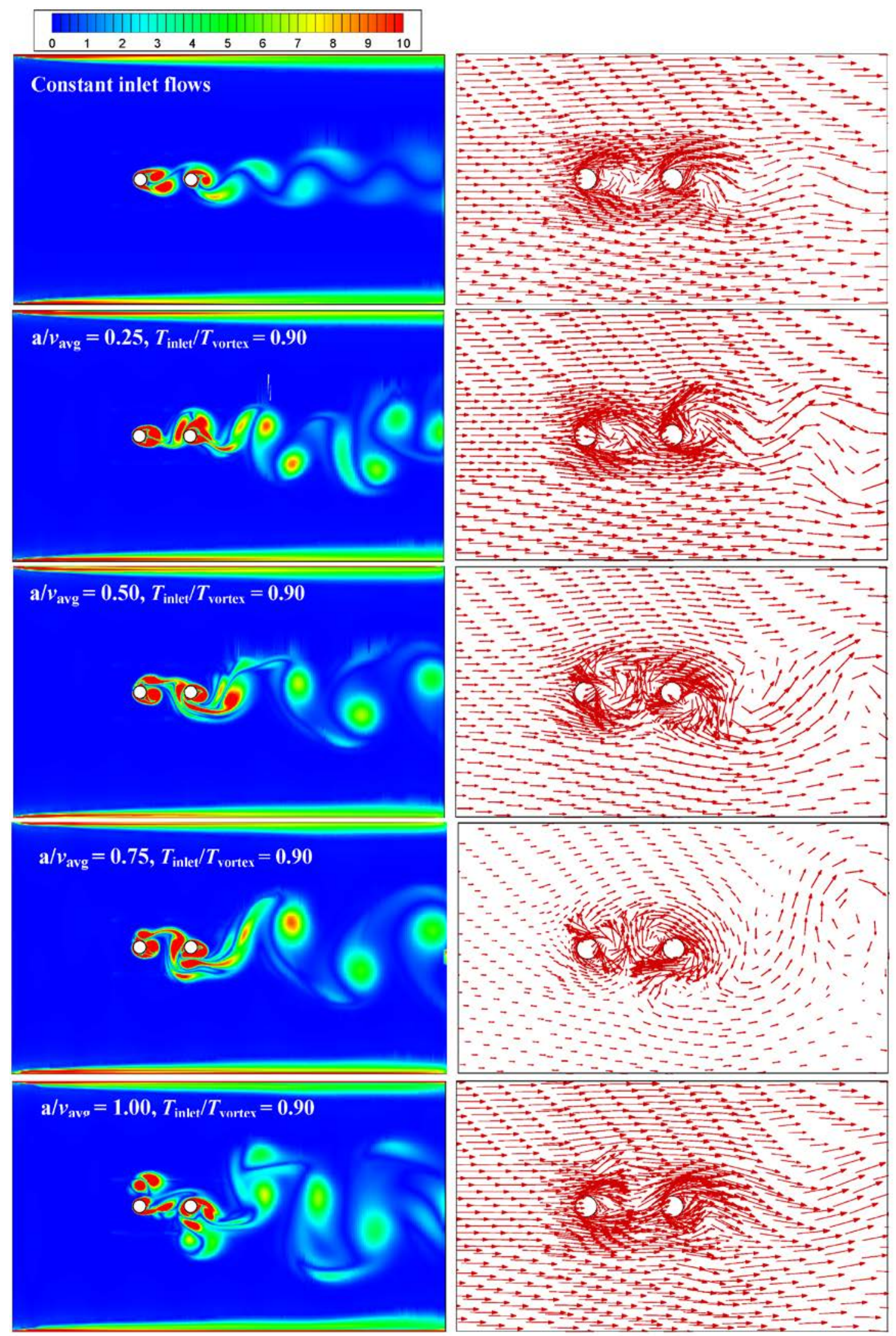

Figure 9. The vorticity magnitude contours and vectors around two cylinders with different amplitude ratios at $R e=200$ and $T_{\text {inlet }} / T_{\text {vortex }}=0.90$. 

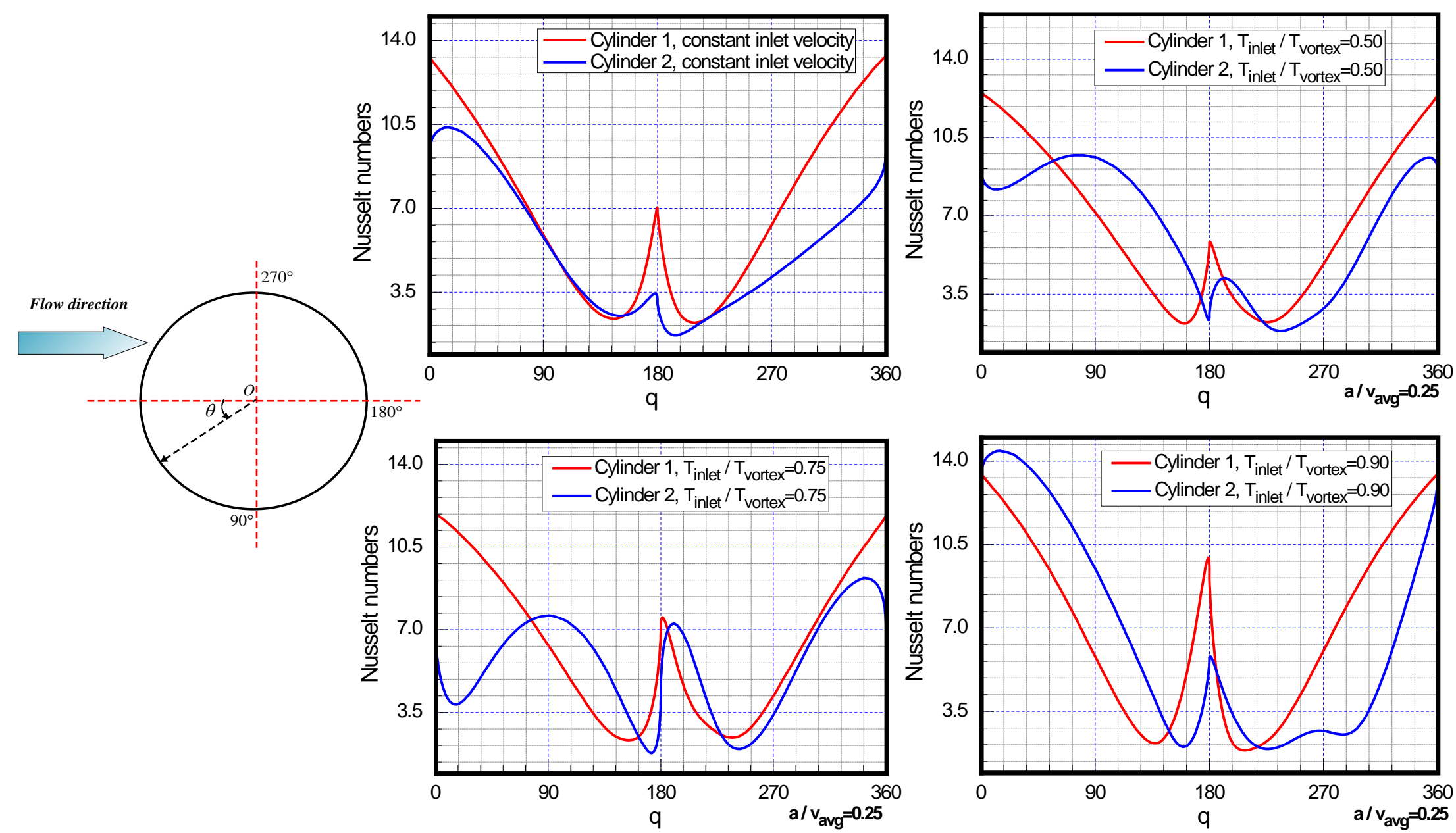

Figure 10. The transient Nusselt number distributions along two cylinders for the cases with different cycle ratios at $R e=200$ and $a / v_{\text {avg }}=0.25$. 

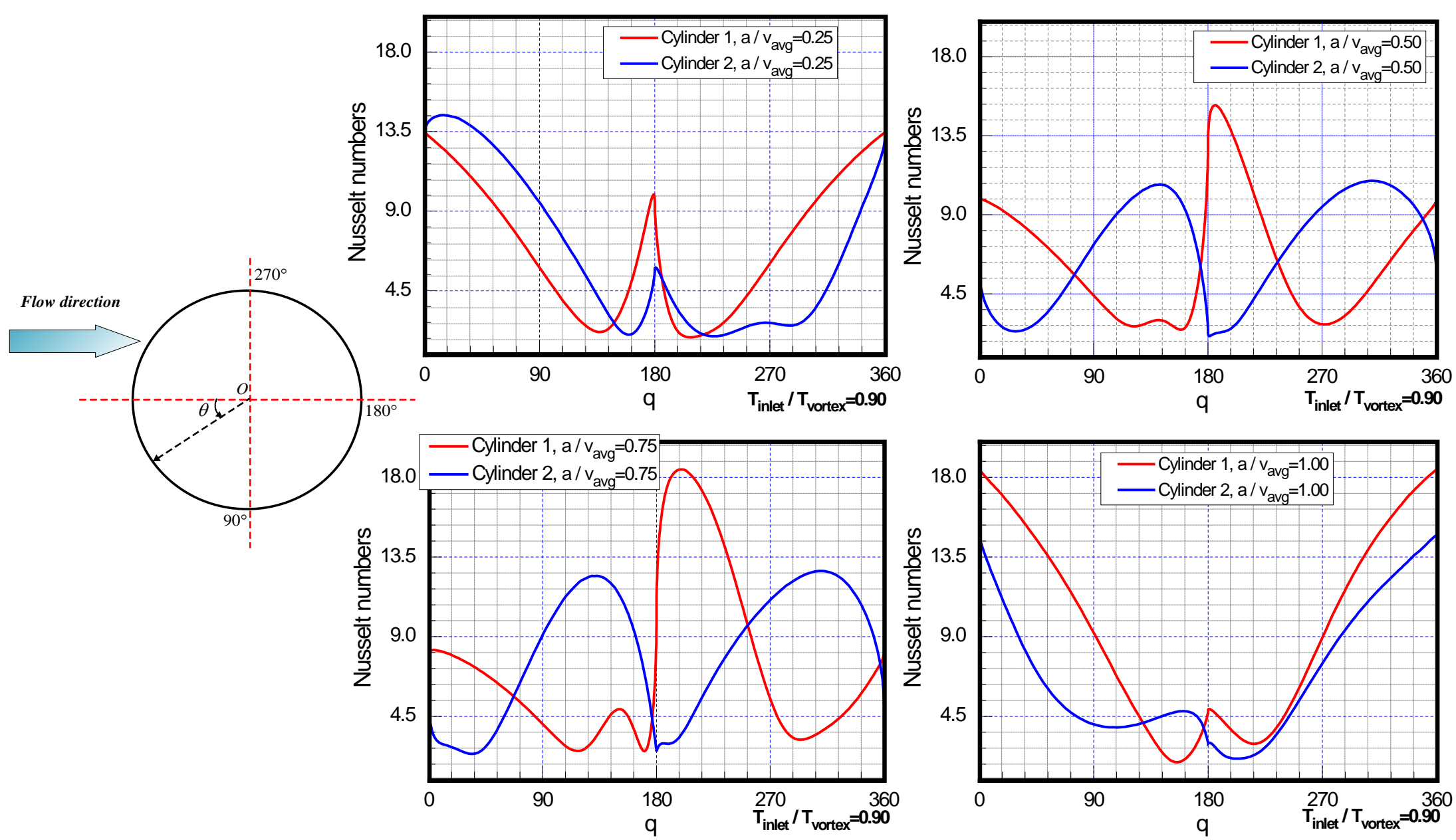

Figure 11. The transient Nusselt number distributions along two cylinders for the cases with different amplitude ratios at $R e=200$ and $T_{\text {inlet }} / T_{\text {vortex }}=0.90$. 

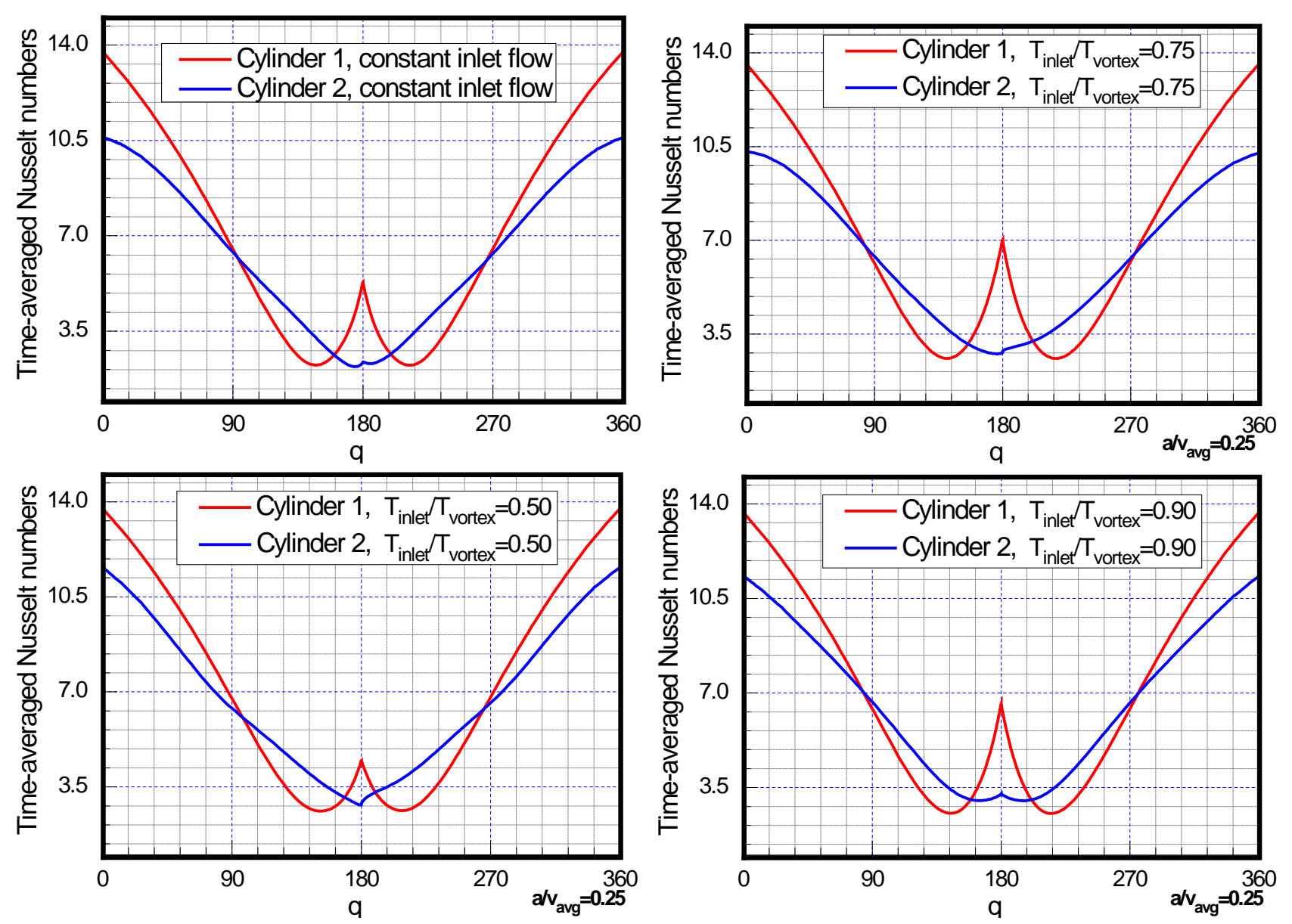

Figure 12. The time-averaged Nusselt number distributions along two cylinders for the cases with different cycle ratios at $R e=200$ and $a / v_{\text {avg }}=0.25$. 

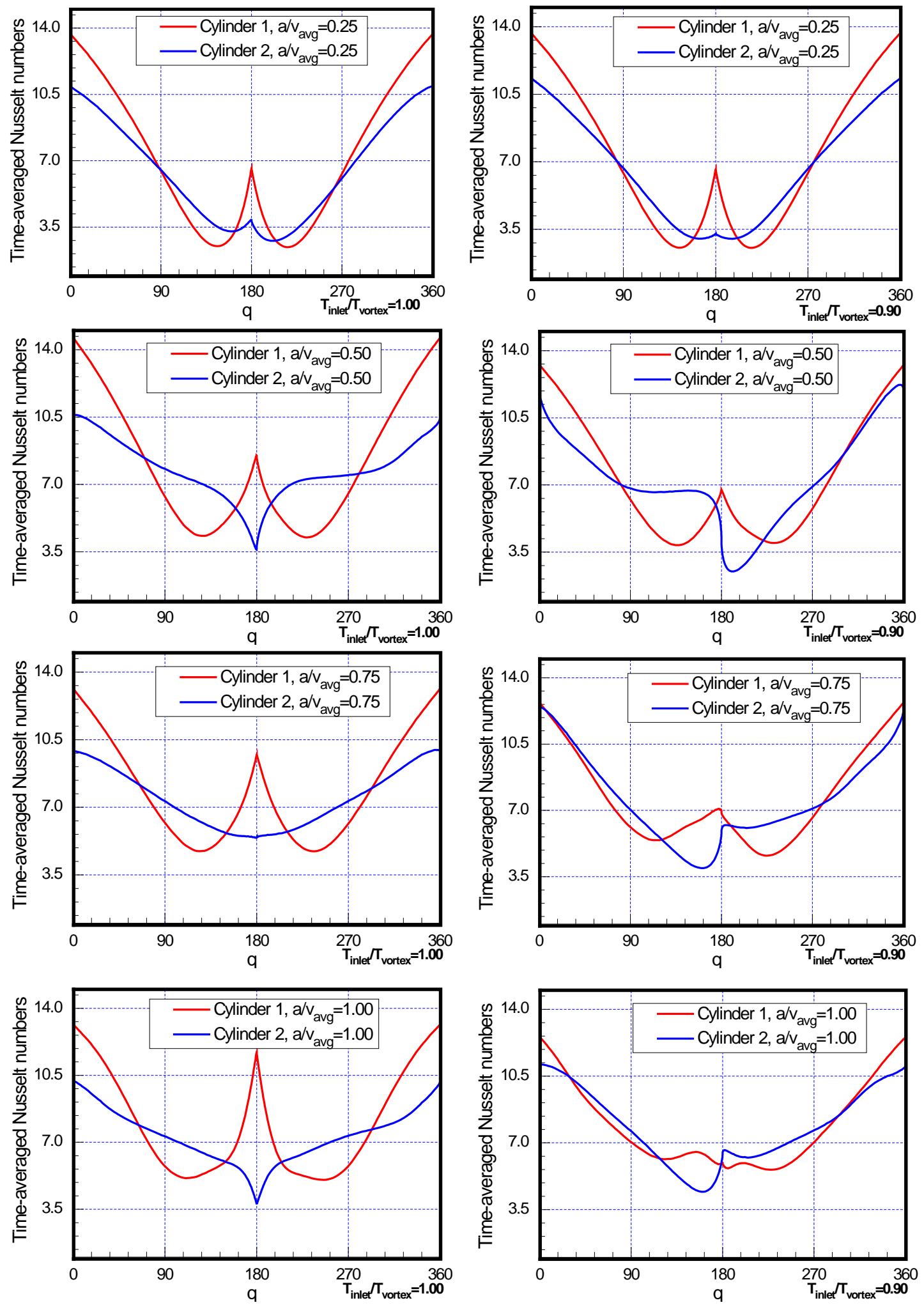

Figure 13. The time-averaged Nusselt number distributions along two cylinders for the cases with different amplitude ratios at $R e=200$. The cycle ratios are controlled by $T_{\text {inlet }} / T_{\text {vortex }}=$ 0.90 and $T_{\text {inlet }} / T_{\text {vortex }}=1.00$. 
Table 1. The mesh independence study for the computational domain with one cylinder at $\mathrm{Re}=200$.

\begin{tabular}{ccccc}
\hline \hline Mesh types & Total meshes & $\boldsymbol{S t}$ & $C_{\mathbf{D}}$ & $\boldsymbol{C}_{\mathbf{L}}$ \\
\hline $\mathbf{y} / \mathbf{D}=\mathbf{0 . 0 1}$ & 42,364 & 0 & 1.434 & 0 \\
$\mathbf{y} / \mathbf{D}=\mathbf{0 . 0 0 7 5}$ & 73.652 & 0.178 & 1.421 & \pm 0.574 \\
$\mathbf{y} / \mathbf{D}=\mathbf{0 . 0 0 5}$ & 10,8973 & 0.183 & 1.367 & \pm 0.637 \\
$\mathbf{y} / \mathbf{D}=\mathbf{0 . 0 0 1}$ & 21,9652 & 0.185 & 1.348 & \pm 0.621 \\
\hline \hline
\end{tabular}

Table 2. The comparisons of averaged Nusselt numbers with previous references.

\begin{tabular}{cccc}
\hline \hline & Present & Eq. (9) & Eq. (10) \\
\hline $\mathbf{R e}=\mathbf{1 2 0}$ & $\mathbf{5 . 8 2}$ & 5.75 & 5.85 \\
$\mathbf{R e}=\mathbf{2 0 0}$ & $\mathbf{7 . 5 8}$ & 7.29 & 7.53 \\
\hline \hline
\end{tabular}

Table 3. The comparison of the calculated results with that in Ref. [17].

\begin{tabular}{ccc}
\hline \hline & Cylinder1/ $\mathbf{N u _ { \text { avg } }}$ & Cylinder2/ $\mathbf{N u _ { \text { avg } }}$ \\
\hline Present research & 7.54 & 6.52 \\
Ref. [17] & 7.43 & 5.96 \\
\hline \hline
\end{tabular}


Table 4. The Nusselt number enhancement of two cylinders in the computational domain with oscillating inlet flow versus different cycle ratios at $R e=200$. The Nusselt numbers of the case with constant inlet flow are provided for comparison.

\begin{tabular}{|c|c|c|c|}
\hline & Frequencies & Cylinder1/ $N u_{\text {avg }}$ & Cylinder2/ $N u_{\text {avg }}$ \\
\hline Case 0 & Constant & 7.54/baseline & 6.52/baseline \\
\hline Case 1 & $T_{\text {inlet }} / T_{\text {vortex }}=0.50$ & $7.59(+0.663 \%)$ & $7.00(+7.361 \%)$ \\
\hline Case 2 & $\mathbf{T}_{\text {inlet }} / \mathbf{T}_{\text {vortex }}=0.55$ & $7.65(+1.458 \%)$ & $6.72(+3.067 \%)$ \\
\hline Case 3 & $T_{\text {inlet }} / T_{\text {vortex }}=0.60$ & $7.69(+1.989 \%)$ & $6.64(+1.840 \%)$ \\
\hline Case 4 & $T_{\text {inlet }} / T_{\text {vortex }}=0.65$ & $7.62(+1.061 \%)$ & $6.67(+2.300 \%)$ \\
\hline Case 5 & $T_{\text {inlet }} / T_{\text {vortex }}=0.70$ & $7.61(+0.928 \%)$ & $6.61(+1.380 \%)$ \\
\hline Case 6 & $\mathbf{T}_{\text {inlet }} / \mathbf{T}_{\text {vortex }}=\mathbf{0 . 7 5}$ & $7.74(+2.652 \%)$ & $6.42(-1.533 \%)$ \\
\hline Case 7 & $T_{\text {inlet }} / T_{\text {vortex }}=0.80$ & $7.74(+2.717 \%)$ & $6.56(+0.613 \%)$ \\
\hline Case 8 & $T_{\text {inlet }} / T_{\text {vortex }}=0.85$ & $7.75(+2.785 \%)$ & $6.64(+0.184 \%)$ \\
\hline Case 9 & $T_{\text {inlet }} / T_{\text {vortex }}=0.90$ & $7.72(+2.297 \%)$ & $6.73(+3.334 \%)$ \\
\hline Case 10 & $T_{\text {inlet }} / T_{\text {vortex }}=0.95$ & $7.72(+2.295 \%)$ & $6.71(+2.995 \%)$ \\
\hline Case 11 & $T_{\text {inlet }} / T_{\text {vortex }}=1.00$ & $7.68(+1.849 \%)$ & $6.60(+1.295 \%)$ \\
\hline Case 12 & $T_{\text {inlet }} / T_{\text {vortex }}=1.05$ & $7.66(+1.605 \%)$ & $6.54(+0.289 \%)$ \\
\hline
\end{tabular}


Table 5. The Nusselt number enhancement of two cylinders in the computational domain with oscillating inlet flows versus different amplitude ratios at $R e=200$. The cycle ratios are set as $T_{\text {inlet }} / T_{\text {vortex }}=1.00$ and $T_{\text {inlet }} / T_{\text {vortex }}$ $=0.90$, respectively.

(a) $T_{\text {inlet }} / T_{\text {vortex }}=1.00$

\begin{tabular}{|c|c|c|c|}
\hline & Amplitude Ratio & Cylinder1/ $\mathrm{Nu}_{\text {avg }}$ & Cylinder2/ $\mathrm{Nu}_{\mathrm{avg}}$ \\
\hline Case 0 & Constant & 7.54/baseline & 6.52/baseline \\
\hline Case 1 & $\mathrm{a} / v_{\text {avg }}=0.25$ & $7.68(+1.849 \%)$ & $6.60(+1.295 \%)$ \\
\hline Case 2 & $\mathrm{a} / v_{a v g}=0.5$ & 7.97(+5.686\%) & $6.93(+6.405 \%)$ \\
\hline Case 3 & $\mathrm{a} / v_{\text {avg }}=0.75$ & $8.26(+9.551 \%)$ & $7.21(+10.67 \%)$ \\
\hline Case 4 & $\mathrm{a} / v_{a v g}=1$ & $8.83(+17.02 \%)$ & 7.06(+8.328\%) \\
\hline
\end{tabular}

(b) $T_{\text {inlet }} / T_{\text {vortex }}=0.90$

\begin{tabular}{cccc}
\hline \hline & Amplitudes & Cylinder1/ $\mathrm{Nu}_{\text {avg }}$ & Cylinder2/ $\mathrm{Nu}_{\mathrm{avg}}$ \\
\hline Case 0 & Constant & $\mathbf{7 . 5 4} /$ baseline & $\mathbf{6 . 5 2 / \text { baseline }}$ \\
Case 1 & $\mathbf{a} / \boldsymbol{v}_{\text {avg }}=\mathbf{0 . 2 5}$ & $7.72(+2.387 \%)$ & $6.73(+3.221 \%)$ \\
Case 2 & $\mathbf{a} / \boldsymbol{v}_{\text {avg }}=\mathbf{0 . 5 0}$ & $7.89(+4.641 \%)$ & $7.44(+14.11 \%)$ \\
Case 3 & $\mathbf{a} / \boldsymbol{v}_{\text {avg }}=\mathbf{0 . 7 5}$ & $8.14(+7.957 \%)$ & $7.90(+21.16 \%)$ \\
Case 4 & $\mathbf{a} / \boldsymbol{v}_{\text {avg }}=\mathbf{1 . 0 0}$ & $8.16(+8.222 \%)$ & $8.01(+22.85 \%)$ \\
\hline \hline
\end{tabular}




\section{Figure and Table Captions}

Figure 1. The schematic configurations of the computational domains,

(a) one cylinder (b) two cylinders.

Figure 2. The oscillating inlet flow with different cycle ratios and amplitude ratios.

Figure 3. The meshes around a cylinder with different boundary layer heights used for numerical verification and the mesh around two cylinders. $y$ is the height of the mesh at the first layer. The grids around two cylinders are also provided in the figure.

Figure 4. The comparison of the drag coefficient and Strouhal number with the experimental data from<Boundary layer theory $>$. (a) Drag coefficient; (b) Strouhal number;

Figure 5. The comparisons of the calculated results with that in previous calculation and experiment. The distribution is the averaged Nusselt number distribution along the cylinder surface at $\operatorname{Re}=120$.

Figure 6. The Nusselt numbers of two cylinders in the computation domain with oscillating inlet flow versus different cycle ratios at $R e=200$. The Nusselt numbers of the case with constant inlet flows are also provided for comparison. The cycle ratio $T_{\text {inlet }} / T_{\text {vortex }}$ ranges from 0.50 1.05

Figure 7. The Nusselt numbers of two cylinders in the computational domain with oscillating inlet flows versus different amplitude ratios at $R e=200$. The Nusselt numbers of the case with constant inlet flow are also provided for comparison. The amplitude ratio a / $v_{\text {avg }}$ ranges from 0.25 to 1.00 . (a) $T_{\text {inlet }} / T_{\text {vortex }}=1.00$; (b) $T_{\text {inlet }} / T_{\text {vortex }}=0.90$;

Figure 8. The vorticity magnitude contours and vectors around two cylinders with different cycle ratios at $R e=200$ and $a / v_{\text {avg }}=0.25$.

Figure 9. The vorticity magnitude contours and vectors around two cylinders with different amplitude ratios at $R e=200$ and $T_{\text {inlet }} / T_{\text {vortex }}=0.90$.

Figure 10. The transient Nusselt number distributions along two cylinders for the cases with different cycle ratios at $R e=200$ and $a / v_{\text {avg }}=0.25$.

Figure 11. The transient Nusselt number distributions along two cylinders for the cases with different amplitude ratios at $R e=200$ and $T_{\text {inlet }} / T_{\text {vortex }}=0.90$.

Figure 12. The time-averaged Nusselt number distributions along two cylinders for the cases with different cycle ratios at $R e=200$ and $a / v_{\text {avg }}=0.25$.

Figure 13. The time-averaged Nusselt number distributions along two cylinders for the cases 
with different amplitude ratios at $R e=200$. The cycle ratios are controlled by $T_{\text {inlet }} / T_{\text {vortex }}=0.90$ and $T_{\text {inlet }} / T_{\text {vortex }}=1.00$.

Table 1. The mesh independence study for the computational domain with one cylinder at $\mathrm{Re}=200$.

Table 2. The comparisons of averaged Nusselt numbers with previous references.

Table 3. The comparison of the calculated results with previous calculations.

Table 4. The Nusselt number enhancement of two cylinders in the computational domain with oscillating inlet flow versus different cycle ratios at $R e=200$. The Nusselt numbers of the case with constant inlet flow are provided for comparison.

Table 5. The Nusselt number enhancement of two cylinders in the computational domain with oscillating inlet flows versus different amplitude ratios at $R e=200$. The cycle ratios are set as $T_{\text {inlet }} / T_{\text {vortex }}=1.00$ and $T_{\text {inlet }} / T_{\text {vortex }}=0.90$, respectively. 